\title{
Huntington's Disease Outpatient Clinic for Functional Diagnosis and Treatment: Coming to Consensus: How Long Term Care Facility Procedures Complement Specialist Diagnosis and Treatment
}

Ruth Veenhuizen ${ }^{\mathrm{a}, \mathrm{j}, *}$, Hanneke Nijsten ${ }^{\mathrm{b}}$, Paul van Roosmalen ${ }^{\mathrm{b}}$, Karen Lammertsen ${ }^{\mathrm{c}}$, Tom Stor ${ }^{\mathrm{c}}$, Lia de Jager ${ }^{\mathrm{d}}$, Jesseke de Man ${ }^{\mathrm{d}}$, Rina van der Doelen ${ }^{\mathrm{e}}$, Karin Landa ${ }^{\mathrm{e}}$, Vera Grond ${ }^{\mathrm{f}}$, Joyce Heffels ${ }^{\mathrm{f}}$, Rinske Groenewoud ${ }^{\mathrm{g}}$, Luce Rovers ${ }^{\mathrm{g}}$, Christian Bakker ${ }^{\mathrm{h}}$, Saskia Leiwakabessy ${ }^{\mathrm{h}}$,

Dirk van der Wedden ${ }^{\mathrm{i}}$, Jacqueline van Blitterswijk ${ }^{\mathrm{i}}$ and Dieuwke van den Bosch ${ }^{\mathrm{a}}$

${ }^{\mathrm{a}}$ Noorderbreedte Care group, Leeuwarden, The Netherlands

${ }^{\mathrm{b}}$ Archipel, Knowledge Centre for Specialized Care, Eindhoven, The Netherlands

${ }^{\mathrm{c}}$ Huntington Expert Centre Atlant, Apeldoorn, The Netherlands

${ }^{\mathrm{d}}$ Huntington Centre Topaz Overduin, Katwijk, The Netherlands

${ }^{\mathrm{e}}$ De Riethorst Stromenland, Raamsdonksveer, The Netherlands

${ }^{\mathrm{f}}$ Land van Horne, Weert, The Netherlands

${ }^{\mathrm{g}}$ Amstelring, Amsterdam, The Netherlands

${ }^{\mathrm{h}}$ Florence Care Group, The Hague, The Netherlands

${ }^{i}$ Dutch Huntington's Disease Association, The Hague, The Netherlands

${ }^{\mathrm{j} D e p a r t m e n t}$ of Epidemiology and Biostatistics, Amsterdam Public Health research institute, VU University Medical Center, Amsterdam, The Netherlands

\begin{abstract}
Huntington's disease (HD) patients and families deserve expert treatment and care throughout their lives, but uniformity in functional diagnosis and treatment was lacking. In the aim of reaching this uniformity on day-to-day treatment and care offered by multidisciplinary outreach teams from Dutch long term care facilities for ambulatory HD patients, a consensus trajectory was started to harmonise our care programme with international standards and within the country. The consensus statements, given as supplementary material, should lead to expert treatment and care for HD families throughout the Netherlands and this manuscript should contribute and revitalise a global discussion on standards of treatment and care.
\end{abstract}

Keywords: Huntington's disease, caregivers, standard of care, consensus, case managers, ambulatory care, outreach clinic 
Huntington's disease (HD) is a neurodegenerative disease usually starting in the 4th or 5th decade of life and leading to dependency and finally death in about 20 years from onset [1]. It is a dominantly inheritable disease caused by an expansion of CAG triplet repeats in the Huntingtin gene on chromosome 4 . The symptoms start slowly and, progressively comprise the behavioural, cognitive, and motor domains. A combination of impairment of functions and involuntary disinhibitions in these domains leads to a disabled and dysfunctioning patient, who frequently spends the last years of the disease in a long term care facility (LTCF). The insidious onset of the disease and the concomitant cognitive decline, changes in behaviour, communicational problems and frequently diminished awareness of these changes by the patient, very often result in serious domestic problems, like quarrels [2]. In the Netherlands people at risk of carrying the mutated gene expansion, can turn to a University clinic for diagnosis of their genetic status. If someone is suspected of manifest HD he/she can go to a specialised neurologist for diagnosis and treatment. In case of psychiatric symptoms, a specialised psychiatrist can be consulted. The general practitioner (GP) can consult these clinicians for advice at home. Increased care dependence, functional decline, behavioural problems and caregiver burden are frequent reasons for admission to a LTCF. And as there is no cure for HD yet, reducing these functional problems may postpone admission to a LTCF. Together with treatment by clinical geneticists, neurologists and psychiatrists this additional functional approach may lead to optimal support for patient and family. In this correspondence article this approach is outlined.

How did it start? In the Netherlands there are 8 specialised LTCFs offering care for about $240 \mathrm{HD}$ residents. It is estimated that there are $1700 \mathrm{HD}$ patients with 6-9000 gene and risk carriers. In 2008 the specialised LTCFs started a nationwide network: 'Huntington Network Netherlands' (HNN) because shortcomings in adequate treatment and care were pointed out by a few dedicated medical professionals and the Huntington lay association. Within this network a shared vision on best treatment and care for HD patients and their families was developed, based on the standards of Care model (see Fig. 1) developed by Simpson et al. [3] within the European Huntington's Disease Network (EHDN). This vision includes "access for all HD-patients and their relatives to expert professionals, all over the country, from being born in an HD-family until death". Within $\mathrm{HNN}$ a care programme based on international and national guidelines concerning HD was written, which focussed specifically on treatment and care offered to HD patients living at home [3]. Multidisciplinary teams from the LTCFs (psychologists, physiotherapists, occupational therapists, speech and language therapists, social workers, nurses, dieticians and LTCF-doctors) offer their specialised treatment and care to these ambulatory patients in an outpatient clinic (OC). By organising coordinated outreach care and treatment at home, it was hypothesised that patients' living at home could be expanded, without inacceptable burden to the informal caregivers. Over the last year our routines are harmonised through a consensus trajectory. The results of which are given as Supplementary Material. Special funding for this innovative form of outreach treatment $[4,5]$ was obtained in collaboration with a health care insurance company (De Friesland Zorgverzekeraar) and is provided in the form of an innovation subsidy by the Dutch Healthcare Authority.

What is this form of treatment and why should we offer it to patients? In the OC, the patient is seen twice a year for a functional multidisciplinary assessment of the consequences of HD in a systematical order (SAMPC). Somatic functions like consequences of chorea (e.g. falling, decreased mobility, etc.) fatigue, decrease in weight, etc., ADL (Activities of Daily Living) functions like household chores, hobbies, dressing, seating, etc., Social (Maatschappelijk in Dutch) functions like keeping a job, financial responsibilities and family matters, being a parent etc., Psychological functions like memory, mood, executive functioning, coping with functions like being a parent etc., and finally Communicational functions like speaking, language skills etc. are all questioned and/or tested. Family members are invited and their estimation of the patient functioning and the caregiver burden is also systematically ordered. During the assessments by the professionals, patient and family wishes are translated from the functional impairments. From here definition of problems and treatment goals are formulated and prioritised in a multidisciplinary deliberation, leading to a treatment and care proposal for patient and family. Through shared decision making, this proposal is transformed in a personalised treatment and care plan (TCP) at home. In the framework of this plan specialists, like neurologist and psychiatrist, can perform their diagnosis and treatment cycles. Management of the TCP lies in the hands of the professional responsible for the shared decision making process and implies heading/leading of therapists in the home setting. We offer 


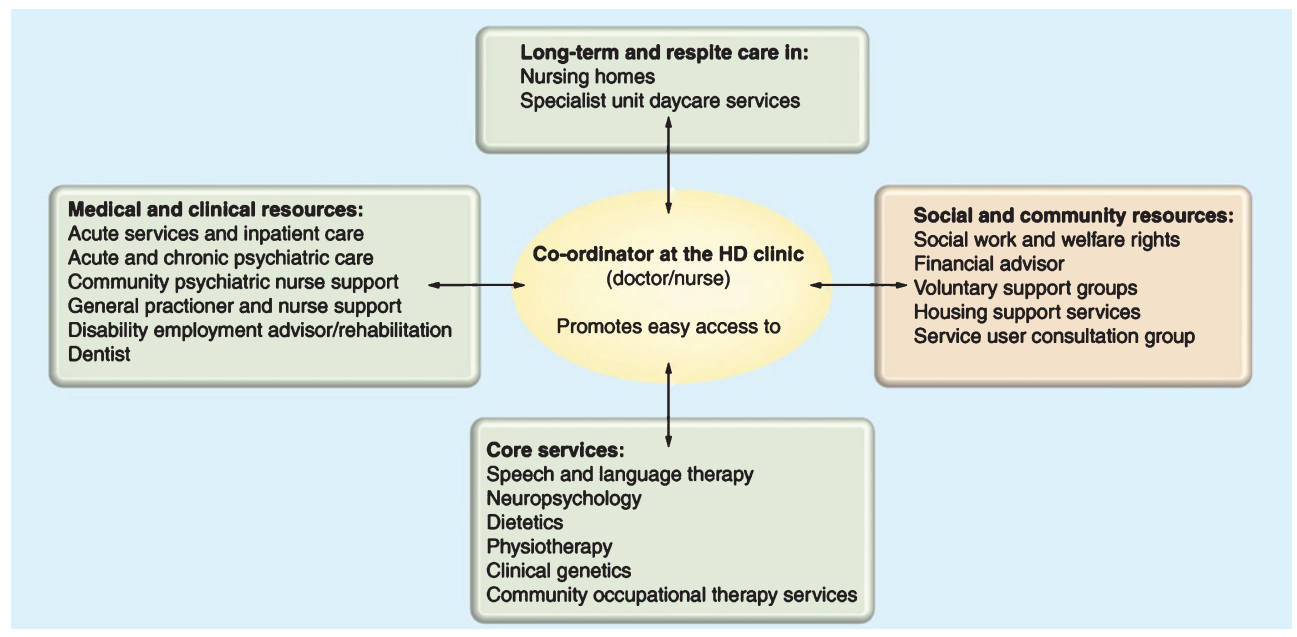

Fig. 1. The care pathway within a managed care network. Redrawn with permission from the European Huntington's Disease Network Standards of Care Working Group. https://www.futuremedicine.com/doi/pdf/10.2217/nmt.11.85

this coordinated TCP with functional goals for patient and family because HD is a multidisciplinary disorder and none of the involved specialists (neurologist, psychiatrist, LTCF- physician, clinical neuropsychologist, physiotherapist etc.) should treat the patient and family independently. In the Dutch LTCF's a problem oriented goal directed approach is prevailing and hence LTCF-specialised professionals are trained in this approach for dependent patients. This consensus supports the literature on multidisciplinary treatment of HD and the general Dutch approach to LTCF-patients. The authors believe that organising a knowledge network in which dedicated nurses, therapists and doctors are working together for individual patients, will lead to functional optimisation of HD-families all over the world.

What did we do until now? In 2017350 patients visited the OC's and this is about $1 / 5$ of the estimated population suffering from actual HD in our country. Since January 2016 we (8 OC's) started to harmonise our working methods, so we only recently began our pioneering work in this field.

Consensus on the working methods of the $\mathrm{OC}$ for HD patients, will not automatically imply treatment and care being of similar quality and content. To make this consensus effective we should strive for regular discussion of efficacy and efficiency of our routines. In collaboration with the global scientific community for $\mathrm{HD}$, indicators should be established and assessment instruments should be tailor-made. Scientific research on the efficacy of multidisciplinary treatment and care for HD patients is scarce and needs to be encouraged through prospective studies in cooperation with academic research institutes all over the world.

\section{CONFLICT OF INTEREST}

The authors have no conflict of interest to report.

\section{SUPPLEMENTARY MATERIAL}

The supplementary material is available in the electronic version of this article: http://dx.doi.org/ 10.3233/JHD-180298.

\section{REFERENCES}

[1] Roos RA. Huntington's disease: A clinical review. Orphanet J Rare Dis. 2010;5:40.

[2] Eddy CM, Parkinson EG, Rickards HE. Changes in mental state and behaviour in Huntington's disease. Lancet Psychiatry. 2016;3(11):1079-86.

[3] Simpson SA, Rae D. A standard of care for Huntington's disease: Who, what and why. Neurodegener Dis Manag. 2012;2(1):1-5.

[4] Veenhuizen RB, Tibben A. Coordinated multidisciplinary care for Huntington's disease. An outpatient department. Brain Res Bull. 2009;80:192-5.

[5] Veenhuizen RB, Kootstra B, Vink W, Posthumus J, Van Bekkum P, Zijlstra M, et al. Coordinated multidisciplinary care for ambulatory Huntington's disease patients. Evaluation of 18 months of implementation. Orphanet J Rare Dis. 2011;18;6:77. 